\title{
Electrochemical Sensor Based on Glassy Carbon Electrode Modified by Palladium Doped ZnO Nanostructures for Glucose Detection
}

\author{
Qingshan Yuan ${ }^{1}$, Zunju Zhang ${ }^{2, *}$, Lei Li $^{1}$ \\ ${ }^{1}$ Northeast Petroleum University, Department of petroleum and chemical engineering, \\ Qinhuangdao,Hebei 066004,China \\ ${ }^{2}$ Hebei University of Environmental Engineering, Qinhuangdao, Hebei 066004, China \\ *E-mail: zhangzunju@ sina.com
}

doi: $10.20964 / 2020.06 .80$

Received: 13 February 2020 / Accepted: 5 April 2020 / Published: 10 May 2020

\begin{abstract}
An electrochemical glucose sensor based on a glassy carbon electrode (GCE) decorated by palladium (Pd) doped ZnOnanorods (NRs) was developed. The Pd-doped ZnO NRs was prepared by a facile chemical bath deposition technique, and the characterizations of the samples were studied byX-ray diffraction and scanning electron microscopy analysis. Electrochemical behaviors of the Pd-doped $\mathrm{ZnO}$ NRs/GCE electrode to glucose were determined by electrochemical impedance spectroscopy, cyclic voltammetry and differential pulse voltammetry. The electrochemical results indicated that the Pd-doped $\mathrm{ZnO} \mathrm{NRs} / \mathrm{GCE}$ revealed an excellent responseto glucose with a detection limit of $0.3 \mu \mathrm{M}$ and a sensitivity of $0.64 \mu \mathrm{A} / \mu \mathrm{Mcm}^{2}$.This sensor was applied satisfactorily to glucose determination in blood serum samples. With remarkable electrochemical performance, Pd-doped ZnO NRs / GCE can provide a suitable platform in the manufacture of a variety of electrochemical sensors and have a great promise for sensing applications.
\end{abstract}

Keywords: Electrochemical glucose sensor; Doped $\mathrm{ZnO}$ nanostructures; Cyclic voltammetry; Differential pulse voltammetry

\section{$\underline{\text { FULL TEXT }}$}

(C) 2020 The Authors. Published by ESG (www.electrochemsci.org). This article is an open access article distributed under the terms and conditions of the Creative Commons Attribution license (http://creativecommons.org/licenses/by/4.0/). 